\title{
Nas Trilhas do Cuidado: A Afirmação da Dimensão Sensível da Experiência na Abordagem Gestáltica
}

\section{On the Tracks of Care: The Affirmation of the Sensitive Dimension of Experience in the Gestaltic Approach}

\section{Sobre las Pistas del Cuidado: La Afirmación de la Dimensión Sensible de la Experiencia en el Enfoque Gestáltico}

\author{
Laura Cristina de Toledo Quadros* \\ Universidade do Estado do Rio de Janeiro - UERJ, Rio de Janeiro, Rio de Janeiro, \\ Brasil
}

\section{Eleonôra Torres Prestrelo**}

Universidade do Estado do Rio de Janeiro - UERJ, Rio de Janeiro, Rio de Janeiro, Brasil

\begin{abstract}
RESUMO
O artigo em questão busca discorrer acerca das exigências, ou melhor dizendo, das convocações que a tarefa de atuar e ensinar Gestalt-terapia nos traz, considerando algumas peculiaridades que atravessam esse fazer gestáltico no contexto acadêmico. Ressaltamos que o eixo central de nossa narrativa apoia-se na ideia do cuidado enquanto prática e intervenção nas múltiplas ações e proposições que constituem a formação universitária em psicologia, perpassando pela nossa compreensão e atuação na clínica gestáltica. Ao afirmarmos a dimensão sensível da abordagem gestáltica, discutimos a articulação da sensibilidade e do cuidado como uma política ontológica, destacando a responsabilidade que temos de produzir mundos com nossas práticas. Nesse sentido, o texto tem a proposição de discutir e pensar nossas práticas durante todos esses anos na interseção entre a universidade, a clínica e a vida. Esse movimento, portanto, enfatiza a impossibilidade de separação entre tais aspectos numa abordagem visionária como é a Gestalt-terapia, cujo fundamento principal é a experimentação. Finalizamos ressaltando a importância da valorização das pequenas ações, afastando-nos de uma certa espetacularização desse fazer, cuja a dimensão política se desdobra no cotidiano.
\end{abstract}

Palavras-chave: gestalt-terapia, cuidado, psicologia clínica, dimensão sensível.

\begin{abstract}
The article in question seeks to discuss the demands, or rather, the calls that the task of acting and teaching Gestalt-therapy brings us, considering some peculiarities that go through this gestaltic practice in the academic context. We emphasize that the central axis of our narrative is based on the idea of care as a practice and intervention in the multiple actions and propositions that constitute the university education in psychology, going
\end{abstract}


through our understanding and performance of the gestaltic clinic. In affirming the sensitive dimension of the gestaltic approach, we discuss the articulation of sensitivity and care as an ontological policy, highlighting the responsibility we have to produce worlds with our practices. In this sense, the text proposes to discuss and to think about our practices during all these years at the intersection between the university, the clinic and life. This movement, therefore, emphasizes the impossibility of separation between such aspects in a visionary approach such as Gestalt-therapy, whose main foundation is experimentation. We conclude by emphasizing the importance of valuing small actions, moving away from a certain spectacularization of this doing, whose political dimension unfolds itself in daily life.

Keywords: gestalt-therapy, care, clinical psychology, sensitive dimension.

\section{RESUMEN}

El artículo en cuestión busca discutir las demandas, o mejor dicho, las llamadas que nos trae la tarea de actuar y enseñar terapia Gestalt, considerando algunas peculiaridades que atraviesan esto hacer gestáltico en el contexto académico. Destacamos que el eje central de nuestro relato se basa en la idea del cuidado como práctica e intervención en las múltiples acciones y propuestas que constituyen la formación universitaria en psicología, pasando por nuestra comprensión y actuación en la clínica gestáltica. Al afirmar la dimensión sensible del enfoque gestáltico, discutimos la articulación de la sensibilidad y el cuidado como una política ontológica, destacando la responsabilidad que tenemos de producir mundos con nuestras prácticas. En este sentido, el texto propone discutir y reflexionar sobre nuestras prácticas durante todos estos años en la intersección entre la universidad, la clínica y la vida. Este movimiento, por lo tanto, enfatiza la imposibilidad de separación entre tales aspectos en un enfoque visionario como la terapia Gestalt, cuyo fundamento principal es la experimentación. Concluimos destacando la importancia de valorar las pequeñas acciones, alejándonos de una cierta espectacularización de este hacer, cuya dimensión política se despliega en la vida cotidiana.

Palabras clave: terapia gestalt, cuidado, psicología clínica, dimensión sensible.

Atuar com a abordagem gestáltica durante tantos anos e manter a ousadia de ensiná-la na universidade, torna-se ao mesmo tempo uma ocupação tão árdua e desafiadora quanto prazerosa. O artigo em questão busca discorrer acerca das exigências, ou melhor dizendo, das convocações que essa tarefa nos traz, considerando algumas peculiaridades que atravessam esse fazer gestáltico no contexto acadêmico. Ressaltamos que o eixo central de nossa narrativa apoiase na ideia do cuidado enquanto prática e intervenção nas múltiplas ações e proposições que constituem a formação universitária em psicologia, perpassando pela nossa compreensão e atuação na clínica gestáltica.

Escrevemos esse texto com a proposição de pensarmos nossas práticas durante todos esses anos na interseção entre a universidade, a clínica e a vida. Esse movimento, portanto, enfatiza a impossibilidade de separação entre tais aspectos para uma 
abordagem visionária como é a Gestalt-terapia (Prestrelo \& Quadros, 2018), cujo fundamento principal é a experimentação. Estudar e ensinar tal abordagem, então, é afastar-se das universalidades e construir um conhecimento dialogado com 0 que vivemos $e$ acompanhamos cotidianamente, seguindo o que ressalta Mol (2008b) ao nos lembrar que "bons estudos de caso inspiram teoria" (p. 11). E assim já iniciamos uma torção metodológica. Não aplicamos uma teoria em nossas práticas a fim de validá-la, como tradicionalmente encontramos como proposta nos trabalhos acadêmicos. Partimos da proposição que nossas práticas performam ${ }^{1}$ mundos, e a melhor maneira de apreendermos o que se dá a nosso conhecimento é seguir a "vida vivida", ou seja, uma vida que se faz na prática, que se "faz, fazendo" 2 .

É a partir dessa ideia que encaminhamos nosso trabalho na universidade: em nossos grupos de supervisão, nos projetos de extensão e pesquisa que coordenamos, nas disciplinas que ministramos, nos simpósios que realizamos e tantas outras ações, valorizando a proposição da construção do conhecimento como processo vivo, ativo, coletivo e desdobrado na premissa de um fazer com o outro e não sobre ele (Quadros \& Moraes, 2016). Esse destaque na preposição com que anima a metodologia de PesquisarCOM, proposta por Moraes (2010), encontra forte ressonância na abordagem gestáltica que traz, em suas bases filosóficas e conceituais, a dialogicidade de Martin Buber e a noção de campo de Kurt Lewin, proporcionando-nos um modo de fazer mais simétrico e integrado.

Partindo da noção de totalidade que inspira a abordagem gestáltica, acolhemos o que se faz figura e, na busca de compreensão da relação figura-fundo, ou seja, da emergência da figura no campo no qual se insere, vamos configurando sensações, sentidos, escolhas, pois numa abordagem gestáltica da vida, essa é a relação que nos constitui, como claramente nos afirmam F. Perls, Hefferline e Goodman:

Em toda e qualquer investigação, psicológica ou sociológica, temos de partir da interação entre o organismo e seu ambiente. Não tem sentido falar, por exemplo, de um animal que respira sem considerar o ar e o oxigênio como parte da definição deste, ou falar de comer sem mencionar a comida, ou de enxergar sem luz, ou de locomoção sem gravidade e um chão para apoio, ou da fala sem comunicadores. . . . Denominemos esse interagir entre organismo e ambiente em qualquer função 'o campo/organismo ambiente' e lembremo-nos de que qualquer que seja a maneira pela qual teorizamos sobre impulsos, instintos, etc., estamos nos referindo sempre a esse campo interacional e não a um animal isolado. (1997, p. 42). 
Considerando tais aspectos, temos nos dedicado às questões contemporâneas com o intuito de poder compreendê-las de forma integrada ao vivido, privilegiando as demandas da comunidade. Nossa proposição de integração do conhecimento se volta para a academia, território onde também atuamos na tentativa de aproximar o conhecimento produzido de uma "vida vivida", aquela que vivemos cotidianamente e na qual enfrentamos, com frequência, formas tão distanciadas do sentir, ao tratarmos dos grandes acontecimentos, bem como dos ditos pequenos (angústias existenciais, enfrentamentos de perdas, modos de existência produtores de ansiedade, etc.), que de pequenos nada têm e, por isso, os denominamos em nossos estudos de pequenos/grandes acontecimentos, aqueles que verdadeiramente performam uma vida. Nesse sentido, ao entrelaçarmos o cuidado como prática e possibilidade no que realizamos, apostamos num modo de fazer gestalt que afirma a dimensão sensível da experiência enquanto base para nossas ações que atravessam a formação em psicologia numa universidade pública, que é pioneira em trazer a Gestalt-terapia como disciplina obrigatória em sua grade curricular.

Nos últimos 12 anos, esse modo de fazer vem ganhando contornos concretos em realizações acadêmicas que demonstram a sedimentação da abordagem gestáltica nas diversas exigências que o campo acadêmico nos faz. Como Programa de Extensão Universitária e Pólo de Estudos Gestálticos, contamos, até o momento, com três projetos de extensão universitária, dois projetos de pesquisa em andamento e dois finalizados, cerca de 45 monografias, 2 dissertações de mestrado em andamento e 2 concluídas, 2 teses de doutorado em andamento, a organização de um livro, além de inúmeras apresentações em congressos, simpósios, jornadas e afins, nacionais e internacionais, bem como diversos capítulos de livros, artigos, resumos publicados e a organização de dois números temáticos na revista Estudos e Pesquisas em Psicologia (o último do qual esse artigo faz parte), afirmando, com isso, um espaço de produção na área. Esse crescimento vem tanto de um esforço de trabalho quanto do aumento de interesse por uma abordagem que integra as emoções em simetria com a razão, que afirma a dimensão sensível da experiência e que se coaduna com um modo de fazer ciência que considera sua indivisibilidade com a vida.

\section{Do resgate à afirmação da dimensão sensível da experiência: desafios, surpresas e convocações desse fazer gestáltico}

Tivemos oportunidade anterior (Prestrelo \& Quadros, 2009, 2011, 2018; Quadros \& Prestrelo, 2015) de ressaltar o caminho realizado pela abordagem gestáltica em busca da afirmação de um modo de 
intervir que integrasse razão e sensibilidade, sem que uma se subordinasse a outra, sendo o experimento um dos norteadores dessa relação. Porém, vale destacar os cuidados que o compõe:

Cabe aqui esclarecer que o experimento não é uma técnica que pode ser recortada de um sistema epistemológico. Este é um erro que foi reproduzido durante anos, gerando uma série de equívocos em relação à Abordagem Gestáltica. O experimento não é uma superprodução ou um mero recurso de expressão catártica. Na verdade, ele precisa ser manejado de forma sutil, pois seu diferencial consiste em permitir que o cliente experiencie a si mesmo através do que expõe, integrando sua fala à percepção de seu sentimento, sua postura corporal e suas potencialidades e limitações no contexto de sua experiência viva. Assim, ele reconfigura sua perspectiva, ampliando seu fluxo de consciência na ação em que vive. (Prestrelo \& Quadros, 2009, p. 13).

Pelo exposto, o experimento é um processo que deve emergir do movimento estabelecido no campo relacional no qual ele se inscreve. Isso exige uma legitimação dos sentidos e do sentir e, a nosso ver, ao transpor as bases da filosofia existencial para a prática clínica, F. Perls abre uma trilha que nos permite o resgate da dimensão sensível da experiência.

Perls desenvolve uma metodologia de vanguarda que preconiza uma visão holística de Homem, integrando corpo, mente e contexto social. Portanto, apesar de sua irreverência, legitimou a sensibilidade e a intuição como modos de intervenção em psicoterapia. (Prestrelo \& Quadros, 2009, p. 13).

Considerando que no âmbito acadêmico há o predomínio de um modelo positivista de ciência, torna-se desafiador traçar um diálogo entre uma abordagem que destaca a sensibilidade como fundamento de sua intervenção e os requisitos de sustentação de uma formação universitária. Um dos pontos primordiais é não descaracterizar a abordagem gestáltica e, ao mesmo tempo, não torná-la exótica aos olhos de um conhecimento clássico. Fazemos sim algo diferente, porém, mantemos a seriedade e o rigor nesse fazer marcado pela flexibilidade e pelo olhar sensível. Portanto, ao afirmarmos a dimensão sensível da experiência em nossos fazeres na universidade, buscamos não enquadrá-la num modelo no qual ela não cabe e, dessa forma, evitamos o que chamamos de uma gestalt acadêmica e nos esforçamos por manter uma academia gestáltica, onde o conhecimento sensível mantenha-se valorizado e legitimado em nossos estudos e práticas. 
Desse modo, nossa meta é estimular um conhecimento sensível, primordial, pois assim como nos mostra Duarte (2000):

A educação do sensível nada mais significa do que dirigir nossa atenção de educadores para aquele saber primeiro que veio sendo sistematicamente preterido em favor do conhecimento intelectivo, não apenas no interior das escolas, mas ainda e principalmente no âmbito familiar de nossa vida cotidiana. ( $p$. 15).

Vale ressaltar que não colocamos o saber sensível como maior ou menor do que o intelectivo, mas o entendemos como necessário, em estado de equivalência. Especialmente na formação do psicólogo nossa área de atuação e interesse - a integração do sentir permite uma ampliação tanto dos modos de expressão quanto dos de captação do conhecimento, visto que muito do campo do humano transcende a palavra. Então, a partir desse fundamento, buscamos resgatar, no meio universitário e também na comunidade que nos cerca, uma outra possibilidade de interagir com o mundo, para além do modo essencialmente teórico. Aproximamos o conhecimento de seus aspectos vivos e dinâmicos do cotidiano, e na possibilidade de olhá-lo através do resgate de nossa dimensão sensível, atentandonos para a produção de um saber que "nos passe", um saber de experiência:

A experiência é o que nos passa, o que nos acontece, o que nos toca. Não o que passa, não o que acontece, ou o que toca. A cada dia se passam muitas coisas, porém, ao mesmo tempo, quase nada nos acontece. Dir-se-ia que tudo o que se passa está organizado para que nada nos aconteça. (Bondía, 2002, p. 21).

Ao privilegiarmos em nossos projetos e pesquisas o conhecimento sensível, a partir da abordagem gestáltica, "não só ampliamos o espaço de inserção dessa abordagem, como também criamos um campo coletivo de pesquisa e construção do conhecimento alicerçado no compartilhamento de experiências." (Quadros \& Prestrelo, 2011, p. 180).

Com isso, podemos dizer que gradativamente temos alcançado nossa meta, pelas devoluções que recebemos nos eventos que organizamos, através da avaliação das atividades pela comunidade, pela identificação de nosso projeto como um lugar de escuta de si, do outro e de problematização de temas delicados, e muitas vezes evitados, na instituição. Nossa metodologia de trabalho privilegia rodas de conversa, oficinas vivenciais e intervenções no campo, onde a troca acontece de forma mais implicada, expandindo uma noção da 
clínica muito mais abrangente que aquela praticada entre as quatro paredes de um consultório.

\section{Cuidado e sensibilidade: uma política ontológica para fazer ciência}

Num momento como o que estamos vivendo, onde uma extrema onda de conservadorismo coloca em xeque a própria ciência, há de se ter cautela com o que podemos produzir enquanto suposta verdade. Tradicionalmente, se tem entendido que uma psicologia científica é aquela permeada por comprovações e categorizações. Estando nossa prática afastada dessa lógica, apoiamo-nos na perspectiva trazida por Mol (2008a) e Law (2002) ao nos apresentar a proposição de uma política ontológica na pesquisa:

Política ontológica é um termo composto. Refere-se a ontologia - que na linguagem filosófica comum define o que pertence ao real, as condições de possibilidade com que vivemos. A combinação dos termos 'ontologia' e 'política' sugere-nos que as condições de possibilidade não são dadas à partida. Que a realidade não precede as práticas banais nas quais interagimos com ela, antes sendo modelada por essas práticas. O termo política, portanto, permite sublinhar este modo activo, este processo de modelação, bem como o seu carácter aberto e contestado. (Mol, 2008a, p. 2).

A afirmação acima sublinha a responsabilidade do nosso fazer. Nós, psicólogos, gestalt terapeutas, temos uma incumbência importante na medida em que nossa atuação tem um impacto no coletivo. $\mathrm{Na}$ perspectiva de Mol (2008a) e Law (2002), nossas ações produzem realidades e precisamos estar atentos a que realidades queremos produzir. Este é um dos riscos que corremos. A proposta de F. Perls (1977, 1979, 1981) era a de uma prática libertária, tendo a busca pela autenticidade como norte e a expressão livre como método. Nesse sentido, essa é uma abordagem rebelde, ligeiramente insolente e, a nosso ver, arisca aos enquadres limitadores. Portanto, há em Fritz Perls e notadamente em Laura Perls, sua companheira na vida e na construção dessa abordagem, uma (con)vocação para uma prática em psicoterapia e em psicologia que não se restrinja a interioridade, ao contrário, há uma preocupação constante em compreender a pessoa no e com o seu mundo. Para Fritz Perls, "O homem que pode viver um contato íntimo com sua sociedade, sem ser tragado por ela nem dela completamente afastado, é um homem bem integrado... O objetivo da psicoterapia é justamente criar tal homem." (F. Perls, 1981 , p. 40). Logo, nosso fazer abrange uma dimensão ética, política 
e sensível, visto que os diversos modos de estar no mundo não se reduzem ao intelecto.

Segundo Polster e Polster (2001), nosso modo de apreender o mundo, de fazer contato (conceito fundamental para a abordagem gestáltica) acontece através dos sentidos (tato, olfato, visão, audição, paladar), acrescidos do falar e do movimentar-se. Assim, nossa relação com o que nos rodeia perpassa o nosso corpo, deslocando-se do intelecto como centro de nosso estar no mundo. Dessa maneira, há aqui o resgate da dimensão sensível da experiência como base fundamental para desenvolvermos a prática gestáltica. E o sensível, aqui, faz-se necessário e não apenas coadjuvante.

Refletindo acerca do que nos apontam Mol (2008a) e Law (2002), não podemos nos circunscrever numa prática clínica tradicional de consultório. Buscamos ampliar nossas práticas como docentes, nos desafiando a pensar criticamente as implicações políticas de nossas intervenções. Não mais cabe nos restringir a uma compreensão da clínica psicológica vinculada a um modelo médico, vendo o cliente como alguém sobre o qual nos debruçamos e intervimos através de técnicas e prescrições comportamentais. Aliás, esse olhar se opõe à própria abordagem gestáltica. Trabalhamos orientadas por uma teoria de campo e precisamos estar atentas às suas diversas configurações. Como nos colocou tão claramente Marcia Amendola (2014), é fato que a visão de uma clínica tradicional, que ainda separa psicologia e política, continua predominante para uma significativa parcela das(os) profissionais brasileiras(os). Mas pensar como a realidade social afeta as pessoas é imperativo para que se problematize, de forma ética e política, uma prática psicológica.

Hoje, mais do que antes, não podemos fazer essa dissociação. Nossa abordagem nos coloca desde sempre essa condição, quando F. Perls (1979) afirma que a Gestalt-terapia é muito mais que uma abordagem clínica, pois se configura, antes e acima de tudo, como uma filosofia de vida!

Uma "vida vivida" nos conecta a uma proposição ética que nos orienta as ações no cotidiano dos dias. Como aponta Enila Chagas, em texto de 2006, porém, tão atual:

No aqui e agora que estamos vivendo, que já se prolonga em passado e futuro, a ética aparece a cada momento, na mídia, quase sempre representando apenas uma capa para atender a interesses pessoais. Neste sentido, a ética passa a ser um manto para a hipocrisia. Corremos o risco de assistir a uma banalização do tema ou ao seu esgotamento. Mas é justamente nesses momentos de crise de valores em determinado grupo social que mais se torna necessário pedir socorro à ética, como um princípio inerente a cada um de nós, agindo de forma 
indivisível nos aspectos pessoal e profissional. (Chagas, 2006, p. 2).

Ela nos fala da importância da ética como aspecto fundamental do processo civilizatório do homem, acompanhando e promovendo a organização social desde os primórdios, desde os pré-socráticos. A ética surge para dar conta de questões fundamentais de nossa existência: quem sou eu diante do bem e do mal, conceitualmente falando? Até onde vai minha liberdade e inicia a do outro? Sou um ser de escolhas ou um fantoche das forças culturais e sociais nas quais estou imerso? Questões presentes em alguns ou em muitos momentos de nossa existência. Uma ética que vai muito além da aplicação de códigos normativos. Uma ética que considere, inclusive, o sofrimento como efeito da tentativa de enquadramento e universalização dos sujeitos, desprezando a riqueza e a diversidade das formas de existência.

A partir dos aspectos aqui levantados, voltamos aos autores Mol (2008a) e Law (2002) para reafirmar que, considerando o fundamento da Gestalt-terapia de indivisibilidade pessoa/mundo ( $F$. Perls, 1981; L. Perls, 2004), podemos através das nossas práticas produzir essa ética entrelaçando a sensibilidade e o cuidado. E nessa relação, a abordagem gestáltica nos aponta para o movimento necessário de equilibração organísmica, afirmando a potência de vida em detrimento da ênfase no adoecimento. No rastro dessas proposições, então, nos debruçaremos sobre a afirmação da vida como postura ético-política no fazer gestáltico e, sobretudo, como uma ética do cuidar.

\section{Entre o ordinário e o extraordinário dos dias: o cuidado como política numa "vida vivida"}

Uma das diretrizes de trabalho que temos desenvolvido, e que faz sentido para nós nos últimos anos, é a importância de se olhar o pequeno, o cotidiano, o óbvio, como diria F. Perls (1979). Temos feito isso em nossas pesquisas e escritos, valorizando as narrativas, a proposição de contar histórias de vida como um dispositivo de criação de mundos, pois como diz brilhantemente Eduardo Galeano (2012), não somos feitos de átomos, somos feitos de histórias. Assim, atentarmo-nos aos pequenos acontecimentos nos remete mais uma vez ao sensível, à singularidade, envolvendo nossa humanidade.

Falamos então de uma prática que exige elementos fundamentalmente humanos. A paciência é um recurso, o tato é necessário e a atenção é fundamental, assim como a capacidade de contemplar o que emerge desse ato, como se 
estivéssemos tecendo uma peça artesanalmente, num refinado crochê. Os pequenos acontecimentos promovem o diálogo. A rotina sustenta o encontro, mas nada acontece duas vezes. (Quadros, 2014, p. 38).

Portanto, a dimensão do cuidado se faz fundamentalmente um recurso para acompanharmos as histórias e vidas que atravessam nossa trajetória. Escutar histórias é fazê-las existir, é trazer de volta o encantamento dos dias (Prestrelo, 2017), que nos parece tão necessário na atualidade.

Chimamanda Adichie (2009) nos alerta que "contar histórias importam. Contar muitas histórias importam!", pois quando ficamos com uma única história, ela pode facilmente se transformar num estereótipo, além de ofuscar outras versões. E a questão com estereótipos não é que eles sejam errados, é que são incompletos, superficializam a experiência, invisibilizam o que temos de próprio e de extraordinário em cada um de nós.

Como psicólogas clínicas que somos, ofício onde ouvimos, contamos e recontamos histórias de vida, histórias únicas, singulares, temos resgatado o cuidado de manter a integridade da escuta ao transpô-la para nossas narrativas orais e escritas. Porque nos move acompanhar a vida como ela é! O cotidiano dos dias, "a vida que ninguém vê!" e aparece nas frestas do estabelecido socialmente, na beleza de gestos únicos. Eliane Brum (2012) nos diz que: "Toda vida é uma invenção própria. Não que ela não seja feita de fatos, de dados concretos, de eventos incontroláveis. O que é absolutamente uma criação própria é a forma como cada um olha para a sua vida." (p. 47). E a narra, diríamos.

Para manter a vitalidade dessa discussão, traremos aqui, de forma resumida, um evento narrado pelo gestalt terapeuta americano Michael Vincent Miller (2010) - notas para uma palestra que fez em Cambridge, 1995, numa conferência em memória de Isadore Fromm - que a nosso ver, marca a importância de como as narrativas produzem mundos e, dependendo de como uma história é contada, muito pode se perder no caminho.

Num simpósio no qual participou, organizado em torno de como escolas diferentes de psicoterapia poderiam tratar de assuntos similares, Miller representava a Gestalt-terapia e estava junto de um jungiano, um psicanalista e um terapeuta cognitivo-comportamental. A tarefa era ler a mesma história de um homem jovem e sofrido. Cada um deveria comentar como o abordariam enquanto terapeutas, a partir de suas afiliações teóricas. Depois de lida a história e exemplificada as diferentes intervenções que fariam, fundamentadas em suas orientações teórico-metodológicas, Miller (2010) diz se dar conta, inclusive com sua própria narrativa, que cada vez mais os componentes da mesa, profissionais bem-intencionados e experientes 
em seu ofício, se distanciavam da compreensão desse homem. Parecia não mais falarem dele, esse ser humano sofrido, ao apresentarem configurações teóricas tão elaboradas e brilhantes sobre ele. Na narrativa lida no início, ele era um ser humano comum sofrendo, mas nos diagnósticos de tratamento descritos, o homem gradativamente foi se expandindo e tornando-se algo extraordinário. Eis aí um risco de perdermos de vista o protagonista da história, ou seja, a pessoa em sofrimento. Será que necessitamos do extraordinário para valorizarmos o vivido? Onde ficam postas as experiências ordinárias, costumeiras que, enfim, alimentam nossos dias, performando nossas vidas?

Parece haver uma certa oposição, reflete Miller (2010), entre o ordinário e o extraordinário. E questiona: Eles estão realmente em oposição? Se ambos são levados a existir e se tornam integrados um ao outro, especialmente, se o extraordinário tem suas raízes e cresce de experiências ordinárias, então, há um sentido importante no qual podem estar profundamente ligados. Mas como esses temas se relacionam em nossas práticas acadêmicas?

Pensamos que o desprezo de passagens da vida cotidiana, ordinária, para apenas focalizar os eventos extraordinários, diz muito sobre nossa cultura e valores, além de como isso tende a nos levar tanto à tentativa de sermos extraordinários quanto a buscarmos experiências extraordinárias. Desta forma, o extraordinário deixa de ser o que nos singulariza para tornar-se um padrão, um compromisso, uma ansiedade que nos afasta da espontaneidade.

Refletir acerca dessas questões sugere-nos alguns caminhos interessantes para pensar a respeito da produção de certos sofrimentos contemporâneos: a dificuldade em lidar com a frustração; a necessidade de exposição nas mídias; a busca por determinados modelos corporais, etc. Há quase uma imposição de ser e sentir-se extraordinário!

$\mathrm{Na}$ área da psicologia clínica, nosso campo de atuação, há também uma pressão por modos efetivos de intervenção, marcados por uma eficácia que contraria a imprevisibilidade do humano. E também o perigo da obrigação de atuar de modo extraordinário. Tal e qual a história contada por Michael Vincent Miller (2010), corre-se o risco do abandono de outras possibilidades de ser e estar no mundo, de desconsiderar-se o enfrentamento diário pela saúde, uma saúde que, como nos alerta Canguilhem (2011), não pode ser pura, asséptica, isenta de ranhuras. Se, enquanto psicólogos, especialmente enquanto gestalt terapeutas, nos rendermos à busca pelo extraordinário de forma polarizada, desconsiderando o ordinário, o dia a dia, os pequenos acontecimentos, nos afastaremos de um cuidado cotidiano, artesanal, feito momento a momento, de um cuidado como política fundamental para nossa prática. A lógica do cuidado (Mol, 2008b) é marcada por um olhar sensível e singular, e não por técnicas 
massificadas. Eis aí o desafio, eis aí a ênfase que imprimimos em nossas práticas gestálticas: privilegiar a vida vivida e não simplesmente teorizada.

Cuidar é, pois, uma ação delicada, um recurso construído com o outro que está diante de nós, uma política de relação, levando-se em conta o cotidiano, o que está a nossa volta e o que nos afeta.

\section{Considerações finais: arrematando com cuidado}

Há exatos 10 anos, publicávamos no editorial do primeiro dossiê da abordagem gestáltica da revista Estudos e Pesquisas em Psicologia, um texto em que apresentávamos a Gestalt-terapia como uma abordagem que resgata a dimensão sensível da experiência. Ao pensarmos esse texto, agora em 2019, consideramos pertinente retomar a questão, hoje de um outro lugar, dez anos depois, o que nos leva a substituir a palavra "resgate" por "afirmação". Afirmar a dimensão sensível e entrelaçá-la ao cuidado, potencializa o que apreendemos da abordagem gestáltica. Uma abordagem viva, atual, poética e múltipla. Nada fácil, contrariando críticas e compreensões equivocadas pelos que não a conhecem devidamente (Prestrelo \& Quadros, 2009).

Trazer esse entrelaçamento sensibilidade-cuidado, nos fez percorrer os caminhos de desenvolvimento e expansão da Gestalt-terapia, não apenas em nossa universidade, mas no âmbito universitário em geral. E, como já dito, há nessa caminhada o desafio de mantermos o frescor da abordagem sem descaracterizá-la. Neste sentido, trazemos para essa discussão as dimensões ético-políticas desse fazer com cuidado. Cuidar é também um ato político. Ao seguirmos as trilhas do cuidado, o fazemos a pé, apreciando o que encontramos nesse caminhar, nos juntando para enfrentar os obstáculos, mantendo a artesania de um fazer cotidiano.

Para finalizar, convocamos outra narrativa, dessa vez animada por Laura Perls (2004) em uma entrevista que compõe sua única obra, não traduzida para o português, Vivendo em los limites (Living in the boundering, na publicação americana original). Nessa entrevista, concedida a Daniel Rosenblat em 1984, o entrevistador pergunta como a política e a arte a afetaram, questionando ainda sobre o surgimento da Gestalt-terapia. Então, Laura Perls sabiamente responde:

Naquele momento, a maioria de nós estava envolvida em política de esquerda e me perguntaram por que eu não era mais ativa politicamente, e eu lhes disse: Sabe, creio que o trabalho que faço é um trabalho político. Trabalhar com pessoas tentando fazer com que consigam pensar de forma 
independente, desenredar-se das confluências, é fazer um trabalho político que vai se estendendo, embora só possamos trabalhar com um número muito reduzido de pessoas. Mas estas pessoas podem influenciar outras. Isso quer dizer que esse é um trabalho político. (L. Perls, 2004, p. 55-56, tradução nossa).

Além dessa sábia percepção, ela complementa, ainda:

A terapia é um processo anárquico no sentido de que não segue regras ou normas pré-estabelecidas. Não pretende adaptar ninguém a nenhum sistema, senão adaptar a pessoa ao seu próprio potencial criativo. As atitudes conservadoras se baseiam em grande parte em gestalten fixas. (L. Perls, 2004, p. 56 , tradução nossa).

E, citando um poema de Goethe, ela finaliza dizendo: "A lei e a justiça são herdadas como uma enfermidade eterna na qual a injustiça se converte em justiça e a justiça se converte em injustiça. Portanto, é um ato político fazer terapia." (L. Perls, 2004, p. 56-57, tradução nossa).

Assim vamos seguindo, trabalhando em pequenos grupos, com os alunos nas supervisões, nas salas de aula, com a comunidade em geral que participa de nossos eventos, nos cursos que ministramos, nas palavras e ações com as quais povoamos o mundo. $E$, na contramão do estabelecido, nos encantamos com o ordinário dos dias, pois são eles que fazem o extraordinário da vida e nos afirmam outro modo de fazer ciência.

\section{Referências}

Adichie, C. N. (2009). O perigo de uma história única [Canal de YouTube TED]. Recuperado de https://www.youtube.com/watch?v=D9Ihs241zeg\&t=221s

Amendola, M. F. (2014, Outubro/Novembro/Dezembro). Ética na contemporaneidade e o papel do psicólogo. Jornal do CRP-RJ número 37. Recuperado de http://www.crprj.org.br/site/wpcontent/uploads/2016/01/jornal_37_clinica.pdf

Bondía, J. L. (2002). Notas sobre a experiência e o saber de experiência. Revista Brasileira de Educação, 19(1), 20-28. doi: 10.1590/S1413-24782002000100003

Brum, E. (2012). A menina quebrada e outras colunas de Eliane Brum. Porto Alegre, RS: Arquipélago Editorial.

Canguilhem, G. (2011). O normal e o patológico. Rio de Janeiro, RJ: Forense Universitária. 
Chagas, E. (2006). A ética na psicoterapia: em enfoque gestáltico. Revista da Abordagem Gestáltica, 12(2), 137-142. Recuperado de https://www.redalyc.org/pdf/3577/357735505011.pdf

Duarte, J. F., Jr. (2000). O sentido dos sentidos: a educação (do) sensível (Tese de Doutorado). Faculdade de Educação, Universidade Estadual de Campinas, São Paulo, SP, Brasil.

Galeano, E. (2012). Os filhos dos dias. Porto Alegre, RS: L\&PM Editores.

Latour, B., Rifiotis, T., Petry, F., \& Segata, J. (2015). Faturas/Fraturas: da noção de rede à noção de vínculo. I/ha Revista de Antropologia, 17(2), 123-146. doi: 10.5007/21758034.2015v17n2p123

Law, J. (2002). Aircraft Stories: Decentering the Object in Technoscience (Science and Cultural Theory). Durham: Duke University Press.

Law, J. (2008). On sociology and STS. The Sociological Review, 56(4), 623-649. doi: 10.1111/j.1467-954X.2008.00808.x

Miller, M. V. (2010). Conversa ordinária (comum) - para Isadore. International Gestalt Journal, 33(2), 75-85.

Mol, A. (2008a). Política Ontológica. Algumas ideias e várias perguntas. In J. A. Nunes \& R. Roque (Eds.), Objectos Impuros: Experiências em Estudos sobre a Ciência (pp. 1-24). Porto: Edições Afrontamento.

Mol, A. (2008b). The Logic of Care: Health and the Problem of Patient Choice. London: Routledge.

Moraes, M. (2004). A ciência como rede de atores: ressonâncias filosóficas. História, Ciências, Saúde-Manguinhos, 11(2), 321333. doi: $10.1590 /$ S0104-59702004000200006

Moraes, M. (2010). PesquisarCOM: política ontológica e deficiência visual. In M. Moraes \& V. Kastrup (Eds.), Exercícios de ver e não ver: arte e pesquisa com pessoas com deficiência visual (pp. 26-51). Rio de Janeiro, RJ: Nau Editora.

Perls, F. (1977). Gestalt-terapia explicada. São Paulo, SP: Summus Editorial.

Perls, F. (1979). Escarafunchando Fritz: dentro e fora da lata de lixo. São Paulo, SP: Summus Editorial.

Perls, F. (1981). A Abordagem gestáltica e a Testemunha Ocular da Terapia. Rio de Janeiro, RJ: Zahar Editores.

Perls, F., Hefferline, R., \& Goodman, P. (1997). Gestalt-Terapia. São Paulo, SP: Summus Editorial.

Perls, L. (2004). Viviendo em los limites. México: Plaza y Valdés Editores.

Polster, E., \& Polster, M. (2001). Gestalt-terapia integrada. São Paulo, SP: Summus Editorial.

Prestrelo, E. T. (2017). Histórias que (nos) contem: o encantamento dos dias de uma "vida vivida" (Tese de Doutorado). Instituto de 
Ciências Humanas e Filosofia, Programa de Pós-graduação em Psicologia, Universidade Federal Fluminense, Niterói, RJ, Brasil.

Prestrelo, E. T., \& Quadros, L. C. T. (2009). Abordagem gestáltica: um resgate da dimensão sensível do Humano. Revista Estudos e Pesquisas em Psicologia, 9(1), 10-15. Recuperado de https://www.e-

publicacoes.uerj.br/index.php/revispsi/article/view/9131/7004

Prestrelo, E. T., \& Quadros, L. C. T. (2011). A abordagem gestáltica na universidade: desafio, construção, possibilidades... Revista IGT na Rede, 8(15), 176-185. Recuperado de https://biblat.unam.mx/hevila/IGTnarede/2011/vol8/no15/1.pd $f$

Prestrelo, E. T., \& Quadros, L. C. T. (2018). Gestalt-terapia: da contracultura aos nossos dias, uma abordagem na vanguarda de seu tempo. In V. Darriba \& A. M. L. C. Feijoo (Orgs.), 50 anos de psicologia na UERJ - Psicologia clínica e Psicanálise (pp. 22-33). Rio de Janeiro, RJ: Letra Capital.

Quadros, L. C. T. (2014). O cotidiano de uma Gestalt-terapeuta: a clínica dos pequenos acontecimentos. In E. T. Prestrelo \& L. C. T. Quadros (Eds.), O tempo e a escuta da vida: configurações gestálticas e práticas contemporâneas (pp. 37-50). Rio de Janeiro, RJ: Quartet.

Quadros, L. C. T., \& Moraes, M. O. (2016). Polifonia de uma experiência no ESOCITE. Pesquisas e Práticas Psicossociais, 11(1), 4-7. Recuperado de http://pepsic.bvsalud.org/pdf/ppp/v11n1/01.pdf

Quadros, L. C. T., \& Prestrelo, E. T. (2015). Laboratório gestáltico: a vida vivida, um dispositivo de experimento-ação? VII Prêmio Margarete de Paiva Simões Ferreira: Experiências em Psicologia e Políticas Públicas - Conselho Regional de Psicologia, 7(1), 8797. Recuperado de http://www.crprj.org.br/site/wpcontent/uploads/2016/08/caderno_VII_premio_margarete.pdf

\section{Endereço para correspondência \\ Laura Cristina de Toledo Quadros}

Universidade do Estado do Rio de Janeiro

Instituto de Psicologia

Rua São Francisco Xavier, 524, $10^{\circ}$ andar, Maracanã, CEP 20550-900, Rio de Janeiro - RJ, Brasil

Endereço eletrônico: lauractq@gmail.com

\section{Eleonôra Torres Prestrelo}

Universidade do Estado do Rio de Janeiro Instituto de Psicologia

Rua São Francisco Xavier, 524, $10^{\circ}$ andar, Maracanã, CEP 20550-900, Rio de Janeiro - RJ, Brasil

Endereço eletrônico: eprestrelo@gmail.com 
Recebido em: 13/10/2019

Reformulado em: 20/02/2020

Aceito em: 27/02/2020

\section{Notas}

* Psicóloga, Gestalt terapeuta, Dra. em Psicologia Social/UERJ, Mestre pela FGV/UFRJ, Professora adjunta do Departamento de Psicologia Clínica e da Pós Graduação em Psicologia Social/ UERJ. Supervisora e Chefe do SPA/UERJ.

** Psicóloga, Dra. em Psicologia Social/UFF, Mestre pela PUC-Rio, Terapeuta Comunitária; Professora Assistente e Supervisora de Estágio Especializado em Gestalt-Terapia no Instituto de Psicologia/UERJ; Coordenadora do Programa de Extensão: " COMtextos: arte e livre expressão na abordagem Gestaltica e vice coordenadora do Programa de extensão Laboratório Gestáltico: configurações e práticas contemporâneas".

1 Performar: produzir efeitos. Expressão que pretende distribuir a rede de ações que interfere na produção de um acontecimento. Opõe-se à noção de "atribuição", a partir da proposição que nada se dá a priori. A quem se interessar por essa discussão, ver Law (2008) ou Moraes (2004).

2 "Faz fazer", uma duplicação que a língua francesa preserva e que nos remete ao que nos faz agir, ao que nos coloca em movimento. Uma indicação contrária à noção de causalidade, pois desconstrói qualquer noção de domínio na relação sujeito-objeto e vice-versa, trazendo a simetria para o campo das relações (Latour, Rifiotis, Petry, \& Segata, 2015).

Este artigo de revista Estudos e Pesquisas em Psicologia é licenciado sob uma Licença Creative Commons Atribuição-Não Comercial 3.0 Não Adaptada. 